\title{
Devolution of Water Services, Transformational Leadership and Water Provision in Arid and Semi-Arid Lands in Kenya
}

\author{
Mohamud Mohamed Gedi ${ }^{1}$, Michael Ngala ${ }^{1} \&$ Leonard Wambua $^{1}$ \\ ${ }^{1}$ School of Management and leadership, Management University of Africa, Nairobi, Kenya \\ Correspondence: David Wolf II, School of Management, Northern Canada University, Toronto, ON., M3A 2K7, \\ Canada. Tel: 1-613-947-3592. E-mail: davidwolf@gc.ca
}

Received: January 2, 2018

Accepted: February 3, 2019

Online Published: February 19, 2019

doi:10.5539/ijbm.v14n3p78

URL: https://doi.org/10.5539/ijbm.v14n3p78

\begin{abstract}
The source of livelihood for majority of people in Arid and Semi-Arid Lands (ASAL) is mainly livestock. Thus, water is critical in this region. However, in the ASAL regions this has not been fulfilled as conflicts, human and livestock diseases and waterborne diseases are prevalent due to water shortages. The purpose of this study was to establish the role of devolution of water services, transformational leadership on water provision in Arid and Semi-Arid Lands in Kenya. Specifically, the study determined the influence of devolution of water services on water provision in ASAL in Kenya, established the moderating effect of transformational leadership on the relationship between devolution of water services and water provision in ASAL in Kenya. The study used positivism research orientation.Cross- sectional survey research design was adopted. The target population entailed the 113 sub-counties in ASAL where a sample of 89 sub-counties was targeted. Questionnaire helped in collecting primary data. Secondary data collection was done via desk study. Findings of this study would contribute useful information that would help in the formulation of an action plan for sustainable water management, water conservation and how leaders who inspire, motivate employees can achieve these results. From the findings, the study recommended the need to improve water conservation, protection of catchments and water sources. The study also recommends leaders in ASAL to inspire their subordinates to achieve effective, efficient and sustainable management of both urban and rural water services.
\end{abstract}

Keywords: devolution of water services, transformational leadership, water provision

\section{Introduction}

Researchers have highlighted the problems in water provision in different countries, Kenya included. For instance, a study by Peprah, Oduro-Ofori and Asante-Wusu (2015) in Ghana investigated provision of water in Awutu-Senya East Municipality, Ghana. The study, it was showed that, individuals' contribution on daily water production amounted to $64.2 \%$ with public water provision effort constituting $35.8 \%$. Despite this, $45 \%$ constituted salty water with $28 \%$ being contaminated and impure. In Kenya, Wagah, Onyango and Kibwage (2010) studied accessibility of water services in Kisumu municipality. The findings showed that although $77.1 \%$ of household could access piped water only $25 \%$ accessed the minimum recommended amount. At the same time, low-income households were the most affected by poor accessibility to water. The few studies done locally (Abdumlingo \& Mwirigi, 2014; Kobia \& Bagaka, 2014) are narrow and suffered from conceptual gaps since they only addressed merits and demerits of decentralization governance.

The study by Macharia et al. (2014) also suffered from a contextual gap since it concentrated on Kipipiri constituency while the focus of the current study is on all the 47 counties in Kenya. The study by Simiyu et al. (2014) also faced methodological issues since it was a case study and explored specific contextual area (Kimilili constituency development fund). It is thus apparent that, water provision is an issue that should be investigated in the different contexts with a view to bringing out the issues undermining it. In the Kenyan case, this can only be contextualized to the County administration because water provision is a devolved function. In line with the role of transformational leadership, leaders ought to have the appropriate skills and a wide spectrum of knowledge that would be applied in the appropriate time to address various problems (Serfonten, 2010). Contextualizing this in the Kenyan case and given the issues in water provision in the ASAL as highlighted above, the leadership and management in the Counties with ASAL needs to be interrogated. A critical concern is: how does the leadership style adopted affect the situation? 
The specific objectives are:

1. To determine the influence of devolution of water services on water provision in ASAL in Kenya;

2. To establish the moderating effect of transformational leadership on the relationship between devolution of water services and water provision in ASAL in Kenya;

The study will be beneficial to several stakeholders. The first beneficiaries will be the government of Kenya as by illustrating the effects of management skills on water provision in ASAL regions, policy makers may use the finding of this study to better align or revise the existing legal framework, policies and the guidelines of devolution process. Further, the findings may influence the national government to develop appropriate policies to enhance devolution processes so as to improve water provision to the public and thus propel the country towards achieving Vision 2030. The second beneficiary will be the county governments. The members of county assembly may use the finding of this study to better align or revise the existing county legal framework, to promote water provision in the counties.

This study finally came up with policy recommendations, which can be used by county assemblies and county executives to improve on management and leadership skills so as to increase water provision in county governments. The third beneficiary will be the society as the findings of this study may also benefit the entire Kenyan society including private practitioners by providing them with in-depth understanding of the relationship between devolution and water provision delivery. Similarly, the finding of this study will be of significance to other African developing countries and especially the members of the East African community, that are culturally, economically, and politically similar to Kenya. The last beneficiary will be the scholars and researchers as the framework developed in the study may be useful tool to academicians and other researchers wishing replicate this study in different states, counties and countries. Nevertheless, this study serves as a stepping stone for newer research on devolution, transformational leadership, planning function and water provision.

The study sought to test the following research hypotheses:

$\mathbf{H 0}_{\mathbf{1}}=$ There is no significant influence of devolution of water services on water provision in ASAL in Kenya;

$\mathbf{H O}_{2}=$ There is no significant moderating effect of transformational leadership on the relationship between devolution of water services and water provision in ASAL in Kenya;

\subsection{Importance of the Problem}

Water provision is an issue that should be investigated in the different contexts with a view to bringing out the issues undermining it. In the Kenyan case, this can only be contextualized to the County administration because water provision is a devolved function. In line with the role of transformational leadership, leaders ought to have the appropriate skills and a wide spectrum of knowledge that would be applied in the appropriate time to address various problems (Serfonten, 2010). Contextualizing this in the Kenyan case and given the issues in water provision in the ASAL as highlighted above, the leadership and management in the Counties with ASAL needs to be interrogated. A critical concern is: how does the leadership style adopted affect the situation? Given that there are limited studies that have investigated the issue of devolution of water services in ASAL, there is a dearth of insights to understand the concerns put forward. To address this gap, this study explored the interplay between devolution of water services, leadership styles and water provision in ASAL. To address this gap, this study explored the interplay between devolution of water services, transformational leadership, and water provision in ASAL.

\subsection{Describe Relevant Scholarship}

There are several studies carried out by different scholars in relation to devolution of water services, transformational leadership and water provision in arid and semi-arid lands in Kenya. A study by Wachira (2014) carried a study on challenges and prospects for effective water conservation in Mwingi North District, Kitui County, Kenya. The study adopted an explanatory research design with the sample units being households and institutions. A total of 30 households were sampled using simple random sampling method with medium and low income residential being well represented. The study showed that there is stakeholders' engagement in water conservation though it is not recognized by the local people. A few of them were aware of some NGO's that were involved in community water projects but most of them did not know any of them by name. The stakeholders' engagement showed efforts to provide water projects and also offer community awareness to the community. In relation to transformational leadership, Lee (2012) examined the role of transformational leadership in the home healthcare industry by finding a link between transformational leadership and workplace performance among home health aides. The quantitative research study used secondary data from the 2007 National Home Health Aides survey using binary analysis and multivariate regression analysis. Findings from the study revealed that 
there is a positive relationship between transformational leadership and employee outcome. Employee outcome was measured by reduced injury, increasing career satisfaction, and choosing the same career if they have to choose again.

From a review of existing literature, the kind of leadership and management exercised in the counties can influence the degree to which devolution of the water services enhance the water provision in the society concerned. However, previous studies on devolved services have not adequately addressed this relationship. Due the inadequacies in existing studies, there is a dearth of literature to provide an understanding of the interplay between devolution of water services, leadership styles and efficiency of water provision specifically in ASAL, in consideration of the existing leadership.

The study sought to test the following research hypotheses:

$\mathbf{H 0}_{1}=$ There is no significant influence of devolution of water services on water provision in ASAL in Kenya;

$\mathbf{H O}_{2}=$ There is no significant moderating effect of transformational leadership on the relationship between devolution of water services and water provision in ASAL in Kenya;

$\mathbf{H O}_{3}=$ There is no significant joint effect of devolution of water services, transformational leadership on water provision in ASAL in Kenya.

\section{Method}

\subsection{Participant (Subject) Characteristics}

Each sub-county is headed by a Sub-County Water Officer hence the number of sub-counties in ASAL equals the number of Sub-County Water Officers. The total number of respondents was therefore eighty nine (89). This ensured a naturally heterogeneous but relatively homogeneous sample as recommended by Saifuddin (2009). In the study, questionnaires were administered to Sub-county Water Officer. They were administered through face to face response, where the respondents were asked questions and the researcher recorded the responses in the questionnaire. Proportionate sampling was then used to allocate the proportion of the sample size going to each of the 23 counties. Proportions for this study were effectively applied at county level where the number of sub-counties in each county formed the proportion of sample size going to the county. Random sampling was then applied to select sub-counties. The proportions used were computed as Proportion $(\mathrm{P})=$ Sample Size/Total population $=89 / 113=0.787611$. The study applied a cross- sectional survey as its research design. This is because the variables under study were measured as naturally perceived without manipulation or control.

\subsection{Sampling Procedures}

Proportionate sampling was then used to allocate the proportion of the sample size going to each of the 23 counties. Proportions for this study were effectively applied at county level where the number of sub-counties in each county formed the proportion of sample size going to the county. Random sampling was then applied to select sub-counties. The proportions used were computed as Proportion $(\mathrm{P})=$ Sample Size/Total population $=$ $89 / 113=0.787611$

Proportions for this study were effectively applied at county level where the number of sub-counties in each county formed the proportion of sample size going to the county. Random sampling was then applied to select sub-counties. The proportions used were computed as Proportion $(\mathrm{P})=$ Sample Size/Total population $=89 / 113=$ 0.787611.The computation of sample size for the sub-counties is presented in Table 1 and Table 2 
Table 1. Sample size for the arid sub-counties

\begin{tabular}{llll}
\hline Arid Counties & Arid Sub-county & Proportion & Sample Size (Rounded) \\
\hline Garissa & 6 & 0.787611 & 5 \\
Isiolo & 2 & 0.787611 & 2 \\
Mandera & 6 & 0.787611 & 5 \\
Marsabit & 4 & 0.787611 & 3 \\
Samburu & 3 & 0.787611 & 2 \\
Tana River & 3 & 0.787611 & 2 \\
Turkana & 6 & 0.787611 & 5 \\
Wajir & 6 & 0.787611 & 5 \\
Sub-Total & 36 & & $\mathbf{2 9}$ \\
\hline
\end{tabular}

Table 2. Sample Size for the semi-arid sub-counties

\begin{tabular}{llll}
\hline Semi-Arid Counties & Semi-Arid Sub-county & Proportion & \\
\hline Baringo & 6 & 0.787611 & 5 \\
Embu & 4 & 0.787611 & 3 \\
Kilifi & 7 & 0.787611 & 5 \\
Kwale & 4 & 0.787611 & 3 \\
Laikipia & 3 & 0.787611 & 2 \\
Lamu & 2 & 0.787611 & 2 \\
Makueni & 6 & 0.787611 & 5 \\
Meru & 9 & 0.787611 & 7 \\
Narok & 6 & 0.787611 & 5 \\
Nyeri & 6 & 0.787611 & 5 \\
TaitaTaveta & 4 & 0.787611 & 3 \\
Tharaka Nithi & 3 & 0.787611 & 2 \\
Kitui & 8 & 0.787611 & 6 \\
Kajiado & 5 & 0.787611 & 4 \\
West Pokot & 4 & 0.787611 & 3 \\
Sub-Total & $\mathbf{7 7}$ & $\mathbf{0 . 7 8 7 6 1 1}$ & $\mathbf{6 0}$ \\
TOTAL & $\mathbf{1 1 3}$ & $\mathbf{8 9}$ \\
\hline Soure: Rear & & & \\
\hline
\end{tabular}

Source: Researcher (2017).

The researcher observed several ethical standards and requirements. A researcher should have integrity in research. Research ethics aims at ensuring that the activities done in the research do not adversely affect or harm anyone (Kayunze, 2003). Before field exercises, the researcher got authorization letter from the Management University of Africa and eventually research permit from NACOSTI, Ministry of Interior and National Coordination in every County in ASAL, as well as office of the County Secretary in the areas of this study.

The researcher made an assurance that, the study findings as derived from the analyzed data would ensure integrity with no manipulation whatsoever. At the same time, all the information that would be obtained from the secondary sources and used in this study would be referenced appropriately. Thus, the research instruments in this study were non-invasive. Moreover, data collected was exclusively used for the academic purpose only. Before distributing the instruments, permission was sought from the leaders and management of Devolved governments in ASAL and other concerned institutions as well as the members of the communities involved in the study. 


\subsubsection{Sample Size, Power, and Precision}

The population for this study was 113 sub-countiesin Arid and Semi-Arid lands in Kenya. According to the Ministry of Planning and Devolution Report (2016), there are one hundred and thirteen (113) sub-counties demarcated as Arid and Semi-Arid Lands (ASAL) and distributed within 23 counties in Kenya.

\subsubsection{Measures and Covariates}

This study used questionnaire to collect primary data. Secondary data on the other hand was collected through desk study. For this study, pretesting of the questionnaire was done through piloting to ensure its reliability and consistency. The fundamental importance of piloting is to examine the viability of the anticipated method to be used in the main research (Leon et al., 2011). In general, a $10 \%$ to $20 \%$ of sample size for the main study is recommended for piloting (Osama \&Issa, 2015). In this regard, piloting was conducted on nine sub-counties within ASAL but who were not covered in the final study. This constituted 10.11 percent (9/89) which was adequate for the purpose piloting for this study. The study adopted Cronbach Alpha to determine reliability of research instruments.

\subsection{Research Design}

This study used positivism research orientation. Positivism has been dominant in the social, psychological and behavioural sciences as well as management research (Ridenour \& Newman 2008). This study applied a crosssectional survey as its research design. This is because the variables under study were measured as naturally perceived without manipulation or control.

\subsection{Recruitment}

In this study, primary data was collected through and questionnaires. The researcher trained four research assistants who were engaged in collecting primary data. Secondary data was collected by the researcher himself from records on water provision and related issues. This was done by first seeking authority from the relevant county and sub-county authorities in ASALs. For purposes of collecting data in this study, the questionnaires were administered to the relevant respondents in the institutions.

The researcher was also helped by some local recruited residents to administer questionnaires. The local residents have a grasp of the terrain and were readily available.

\subsection{Intervention or Manipulation Fidelity}

The study relied on self-report, audio recorded and observational data. Each of these data collection methods provides unique information regarding the adherent and competent implementation of an intervention. Researchers selecting a data collection method for implementation fidelity measurement should consider several factors including, feasibility, cost, efficiency, reliability, reactivity, and the ability to collect adequate behavior samples for measuring practitioner adherence and competence.

\subsection{Baseline Data}

The bio data that was collected includes data on economic activity in the areas studied; as well as respondents' gender, level of education, profession and the year they started working in the county. The main economic activities are Agriculture (54.1\%) and Livestock rearing (45.9\%). However, some also practice Small Scale Business (29.7\%) and Mixed farming (18.9\%). The least practiced economic activities are fishing (2.7\%) and Poultry farming (1.4\%).On respondent's gender, findings indicates that a vast majority of water officers are male (98.6\%) with only $1.4 \%$ being female. On educational level, $39.2 \%$ had a Bachelor degree while $35.1 \%$ had a Diploma. A few had Post Graduate Diploma (8.1\%), with 5.4\% having Masters degree Others had Ordinary level (5.4\%); A-Level (4.1\%); PHD (1.4\%).It was apparent that the profession background of an overwhelming majority of the water officers in ASAL Sub Counties is water engineering (95.9\%). Even so, there were few in with a different profession background including accounting (1.4\%), finance $(1.4 \%)$ and water technician (1.4\%).Most of the Sub County Water Officers started working in their respective County governments in 2013 (78.4\%). However, there were some who started working in 2014 (10.8\%); 2015 (6.8\%); $2016(1.4 \%)$ and 2017 $(2.7 \%)$

\subsubsection{Statistics and Data Analysis}

Step-wise regression analysis was used to test the effect of moderating variable on the relationship between independent variable and the dependent variable.

i. $\quad Y_{1}=\beta_{0}+\beta_{1} X_{1}+e$ : this analytical model tests the relationship between independent variable (devolution of water services) and the dependent variable (water provision). 
ii. The analytical model for testing moderating effect of transformational leadership $\left(\mathrm{M}_{1}\right)$ on the relationship between devolution of water services and water provision:

Step 1: $Y=\beta_{2}+\beta_{3} X_{1}+\varepsilon$

Step 2: $\mathrm{M}_{1}=\beta_{4}+\beta_{5} \mathrm{X}_{1}+\varepsilon$

Step 3: $\mathrm{Y}=\beta_{0}+\beta_{6} \mathrm{X}_{1}+\beta_{7} \mathrm{M}_{1}+\varepsilon$

\section{Results}

\subsection{Bio-Data}

Respondents main economic activities were the agriculture (54.1\%) and livestock rearing (45.9\%). On respondent's gender, findings indicates that a vast majority of water officers are male (98.6\%) with only $1.4 \%$ being female. On the education level of the respondents where, $39.2 \%$ had a Bachelor's degree while minority had a PHD (1.4\%). On the profession of the respondents, it was apparent that the profession background of an overwhelming majority of the water officers in ASAL Sub Counties is water engineering (95.9\%). On the Respondents' first year of working in the County leadership most of the Sub County Water Officers started working in their respective County governments in 2013 (78.4\%).

\subsection{Devolution of Water Services and Water Provision}

Descriptive statistics were presented on a 5-point Likert-type scale data that was summarized using measure of distribution (percentages) measures of central tendency (mean, mode, and median) as well as measure of dispersal (standard deviation). Values of mean, mode and median that are relatively close to each other describe data that is highly symmetric and normally distributed. At the same time mean was used in this study to rank prevalence of different factors grouped together with high mean indicating high prevalence. On the other hand, larger standard deviation implies a greater spread in the data.

The first objective sought to determine the influence of devolution of water services on water provision in ASAL in Kenya. From the findings, devolution of water services was found to be highly enhancing the rate at which county government engages local residents to actively participate in water provision decision making processes with mean of 3.64, median of 4.00, mode of 4.00 and standard deviation of 0.97 . Respondents, nonetheless distressed that devolution of water services in the county has led to increase in the number of water management companies $($ mean $=2.43$, median $=2.00$, mode $=1.00$ and standard deviation $=1.24)$. Findings also indicate that the county leaderships have to a moderate extent been engaging members of their respective county and national assembly's as well as professionals to actively participate in water provision decision making processes including seeking valuable advice on emerging efficient water provision techniques and mechanisms.

The findings imply that human capital in water services provision has been moderately impacted by devolution. Human capital is a key aspect in the manoeuvres of the organization (Armstrong, 2008). Inferential statistics were determined at both composite level and indicators level. Inferential statistics on devolution of water services at composite level entailed coefficient of determination (R-Square), analysis of variance as well as regression coefficient. Test for autocorrelation was also performed. On the model Summary on Devolution of Water Services it showed an R-Square of 0.89 with the standard error of estimate being 1.13. This implies that at composite level, devolution of water services significantly influences water provision. The researcher also tested for autocorrelation using Durbin Watson statistic which is always between 0 and 4 where a value of 2 means that there is no presence of autocorrelation in the residuals (prediction errors) from a regression analysis. Values from 0 to less than 2 indicate positive autocorrelation and values from more than 2 to 4 indicate negative autocorrelation.

From the findings, Durbin Watson statistic was 2.077 and therefore the there was no presence of autocorrelation in the residuals from a regression analysis. On the ANOVA statistics on Devolution of Water Services F-Calculated $(1,72)=582.89$ which is greater than F-Critical $(1,72)=3.96$ at 2 -tail test and $95 \%$ confidence level. Results also show p-value $=0.000<0.005$. This further confirms that devolution of water services positively and significantly influences water provision. On the Regression Coefficients on Devolution of Water Services it was that, when devolution of water services is held constant, water provision we remain at 1.993. At the same time, an increase in devolution of water services by one unit would lead to an increase in water provision by 0.275 units with a p-value of $0.000<0.05$. This can be summarized by the following model:

$$
Y=1.993+0.275 X
$$




\subsection{Moderating Effect of Transformational Leadership on the Relationship between Devolution of Water Services and Water Provision}

The second objective was to establish the moderating effect of transformational leadership on the relationship between devolution of water services and water provision in ASAL in Kenya. Findings indicates that, county leaders to a moderate extent do inspire and motivate their staff in order to optimize productivity especially on water services $($ mean $=2.61$; standard deviation $=1.27)$ giving some attention to subordinates and residents when expressing challenges related to water provision ( mean $=2.66$; standard deviation $=1.19$ ).

Results also show that county leaders fairly do challenge their staff to be creative and generate lasting solutions when faced with challenges on water provision $($ mean $=2.64$; standard deviation $=1.27$ ) and county leaders normally tell their subordinates what has to be done and how to do it (mean $=2.61$; standard deviation $=1.27$ ).In particular, the findings imply that County leaders emphasize on incorporating subordinate advice when making final decisions. This concurs with Iqbal, Anwar and Haider (2015) who highlight that transformational style is where the leader engages others in identifying the important goals and formulating strategies to attain the goals. This style has been affirmed to enhance employees' satisfaction, collaboration and commitment as well as a great flexibility in decision making which results in improved service delivery (Denhardt \& Denhardt, 2003).

Inferential statistics on transformational leadership entailed stepwise analysis as generated using coefficient of determination (R-Square), analysis of variance as well as regression coefficient.

\section{Step 1: Testing if $X$ predicts $Y$}

$$
Y=\beta_{0}+\beta_{1} X+a
$$

Findings as shown in show that, when devolution of water services is held constant, water provision will remain at 1.993. At the same time, an increase in devolution of water services by one unit would lead to an increase in water provision by 0.275 units. This can be summarized by the following model:

$$
Y=1.993+0.275 X
$$

\section{Step 2: Testing if $X$ predicts $M$}

$$
M=\beta_{2}+\beta_{3} X+\varepsilon
$$

The researcher encountered a number of challenges related to the research; but the limitations did not have a significant interference with the outcome of the study. Although this study covers all county governments in Kenya, it only used a sample to draw conclusions and inferences, which was as per the research design. Time factor was a limitation as the respondents took longer time than expected. At times the researcher had to personally travel to some remote local authorities where the research assistants failed to make headways. This escalated the costs beyond the budget. The geographical spread of the 23 counties in Kenya made access difficult In addition, some of the respondents found it difficult to fill the questionnaire because they felt giving the information required might jeopardize their jobs; however this was overcome by assurance that the information will not be divulged and is for academic purpose. The study did not obtain $100 \%$ response rate due to unwillingness and unavailability of some targeted respondents given the nature of information to be collected. Further, this was a cross sectional study. Future research needs to carry out a longitudinal study. The other challenges faced was resource limitations during the entire period of the research ranging from time, finances and technical support during the data analysis and thesis development.

Due to logistic challenges, the researcher was not in a position to acknowledge every element within the population and instead only got a representation with the outcome being generalized to the entire population. To mitigate any bias during the sampling, scientific and systematic techniques were used to select the respondents. Respondents were required to give views that have the potential of being subjective to their personal interpretation of the various research questions which would have affected the accuracy and credibility of the outcome. To mitigate this, the researcher undertook a pilot study where research instruments were subjected to reliability and validity tests. The researcher encountered some security challenges especially in Northern Counties bordering Somalia. The researcher mitigated this by getting security escort in these areas.

Further, the study used ordinal scale among others to measure the variables. However, ordinal scale does not give the investigator the level of precision required in a study, especially when strong statistical procedures are to be 
applied (Mugenda, 2008). The respondent was the sole data source for both independent, intervening and dependent variables. Despite the limitations experienced, the quality of the study was not compromised. The study was designed in highly scientific manner following a thorough literature and theoretical review. Moreover, the study was based on a single country using data from Kenya. There is an opportunity to conduct a larger survey in other major cities and countries across the world. It may be interesting to explore the relationship between devolution of water services, transformational leadership, planning function and water provision in arid and semi-arid lands countries that have similar environments to Kenya. All in all, the study was rigorous in its approach analysis, interpretation and reporting of the findings. The implications discussed did not therefore have any material effect on the results and findings of the study

\section{Findings and Discussion}

The findings indicate that county governments in the ASALs use transformational leadership to a moderate extent in delivery of water provision services. In particular, the findings imply that County leaders emphasize on incorporating subordinate advice when making final decisions. Several areas where improvement is evident in water provision as a result of application of modern technologies were highlighted since transformation leadership facilitates real-time monitoring. Technologies such as smart metering, GIS, telecommunication sensors and decision support systems are effective tools for the provision of real-time reliable data. This means that water utilities have the opportunity to make improvements in demand response and in reducing water losses in the water distribution system. There is also reduction in water consumption. ICTs provide the tools needed to create advanced water use efficiency in all sectors. Incorporation of sensors in the water sectors ensures that water is utilized when needed reducing large volumes of water normally lost due to over use. It has also helped to reduce operation costs. Improvement in operational efficiencies mean that administrations cost can be reduced, creating an optimization of expenses. Technology was also asserted to contribute in greater public involvement. One of the benefits of ICTs is the improvement in communication between water management staff and the public which will lead to an enhancement in public awareness with respect to consumption and water usage. This concurs with Iqbal, Anwar and Haider (2015) who highlight that democratic style is where the leader engages others in identifying the important goals and formulating strategies to attain the goals. This style has been affirmed to enhance employees' satisfaction, collaboration and commitment as well as a great flexibility in decision making which results in improved service delivery (Denhardt \& Denhardt, 2003).

Respondents highly attested that county leaders normally incorporate subordinate advice when making final decision (mean $=3.6$, standard deviation $=1.1$ ). Ratings on other aspects were as follows: The County leaders always consider suggestions made by subordinates on water provision as they do not afford adequate time for them (mean $=3.0$, standard deviation $=1.6$ ); For a major decision on water provision to be approved by the county leadership, it must have the approval of each individual or the majority ( mean $=2.7$, standard deviation $=1.2$ ); County leaders always encourage subordinates to express ideas in countering challenges related to water provision $($ mean $=2.6$, standard deviation $=1.1)$.

The county governments appreciate that they have a mix of public servants. The first category is the public servants that they inherited from the national government and, relatively, have some good level of skills and understanding of government operations. The other is staff employed by the county governments upon inception in 2013. There was also concern that most of these were largely employed based on county regional dynamics, clanism, nepotism and other non-professional considerations - mainly to reward political supporters. They, therefore, require greater training support. However, they still need to be capacity-enhanced to adopt the best practices for county governments in water provision. Most significantly, the counties need to undertake demand-driven training programmes based on the mandate and core business of the county governments that is adequately informed by their respective areas of comparative advantage as opposed to supply-driven ones based on personal staff desire.

The findings imply that county governments in the ASALs use transformational leadership to a moderate extent in delivery of water provision service. Transformational leadership is often associated with authoritarian leaders (Choi, 2007). If Leaders in ASAL use transformational leadership, the implication is that they seldom involve all the stakeholders in water provision (Iqbal, Anwar, \& Haider, 2015). This is contrary to the spirit of devolution which according to Shen and Zou (2015) should be about more efficiency and effectiveness through increased stakeholder participation in responding to the constituents' needs. Although autocratic leadership has been associated with improved service delivery where the leader is constantly and continuously present, it may cause adverse effects like hindering innovation among subordinates, triggering rebellion among others which can undermine effectiveness of service delivery in the long run (Gustainis, 2004). 
It has been argued that when organizations find efficient methods to outdo others, the best choice is to emphasize on the leadership effect (Mehra, Smith, Dixon \& Robertson, 2006). Team leaders are critical in determining collective norms, assisting groups to make it in their situations, as well as co-ordination of organizational actions. According to Purcell et al., (2004), intangible assets like styles of leadership, culture, competency, skills and motivation are considered fundamental aspects in organizations capable of combining people, processes and efficient service delivery.

Kinicki and Kreitner (2008) affirmed that transformative leaders are capable of developing valuable change in an organization, instilling in followers great intrinsic motivation and loyalty, newly establishing the future image and stirring followers' commitment to realize the image. The approach consists of the following aspects: individualized attention, inspiring incentive, idealized influence (behavior and attribute) and logical stimulation (Moss \& Ritossa, 2007). Study by Bass, Avoilio, Jung and Berson (2003) portray transformative leadership as having a direct relationship with organizational productivity. This was confirmed by Dumdum, Lowe and Avolio (2002) for the case of private organizations.

The findings also support of the transformational leadership construct by Sarros and Santora $(2001,2002)$ and Alimo-Metcalfe \& Alban-Metcalfe (2000, 2001 \& 2006) provides an extensively well researched and supportive platform that endorses the facets and virtues of the transformational leadership aspect of the visionary paradigm. Avery (2004, p. 34) has further supported and endorsed the transformational leadership as being within the "ideal leadership paradigm, especially for transforming organisations". A raft of authors that have cross-supported the benefits of transformational leadership and publicly bestowed the virtues, as a must have, for an organisation to move forward, have contributed significantly to reinforcing the base model (Bass, 1985a, 1985b; Cacioppe, 1997; Cardona, 2000; Sarros \& Santora, 2001, 2002; Alimo-Metcalfe \& Alban-Metcalfe, 2001, 2006). These authors have provided the substance for the continual evolvement of the transformational leadership and have continually cross-referenced each other, adding their particular thread of evolvement to the transformational leadership construct, therefore, and increasing support. Several qualitative and quantitative studies have empirically presented the evidence to prove that transformational leadership does exist, and its application, provides benefits for individuals, leaders and organizations.

Michel, Lyons and Cho (2011) as well as Babcock Roberson and Strickland (2010) confirms findings of this study that, transformational leadership have a positive correlation with subordinate outcome of intrinsic motivation, self-efficacy, creativity, justice perceptions, work engagement, job performance, positive psychological capital, organizational performance, organization citizenship, and leader effectiveness. Studies have also shown that organizations with transformational leadership are perceived to be effective organizations (van Eeden, Colliers, \& van Deventer, 2008).

Boga and Ensari (2009) examined transformational and transactional leadership styles and their influence on workforce, and concluded that organizations managed by transformational leaders are perceived as more successful under situations of high organizational change in comparison to low organizational change. They suggested that an organization's well-being depends on the employees' perceptions rather than financial data, citing examples of how corporations like Enron misrepresented the financial well-being of the organization. Toor and Ofori (2009) revealed that there is significant relationship between ethical leadership attributes and transformational leadership attributes and effective leadership, employee commitment, and job satisfaction.

\section{Conclusion and Recommendation}

In conclusion the two study objectives were achieved and their respective null hypothesis not accepted. The first objective was to determine the influence of devolution of water services on water provision in ASAL in Kenya. The second objective was to establish the moderating effect of transformational leadership on the relationship between devolution of water services and water provision in ASAL in Kenya. It was therefore concluded that transformational leadership has a positive and significant moderating effect on the relationship between devolution of water services and water provision in ASAL in Kenya.

\section{Acknowledgements}

My sincere gratitude goes to my family and friends due to the support they accorded me in my study. I also express earnest appreciation to my supervisors Dr. Leonard Wambua and Dr. Michael Ngala because they have assisted me by providing direction and guidance. My special appreciation also goes to the entire teaching and non-teaching staff of the School of Management and Leadership whose contribution and support have helped me reach this far in my studies. God bless you all. 


\section{References}

Armstrong, M. (2008). Strategic Human Resource Management: A Guide to Action. London. Kogan Page.

Choi, S. (2007). Transformational leadership: the lessons of exemplary models for transformational governance. International Journal of Leadership Studies, 2(3), 243-262

Gambe, T. R. (2013). Stakeholders' engagement in water provision: Lessons from Msasa park, Harare, Zimbabwe. International Journal of Politics and Good Governance, 4(42), 1-21

Gustainis, J. J. (2004). Transformational Leadership. Encyclopedia of Leadership, 68-72.

Iqbal, N., Anwar, S., \& Haider, N. (2015). Effect of transformational leadership on employee performance. Arabian Journal of Business and Management Review, 5(5), 1-6

Kayunze, K. (2003). Social Science Research Methods - DS 300 Notes. Development Studies Institute, Sokoine University of Agriculture, Morogoro.

Keith, K. M. (2009). Servant leaders. Leadership Excellence, 26(5), 18-27.

Kobia, M., \& Bagaka, O. (2014). Separation of Powers in Kenya's Devolved Administrative System: Opportunities and Challenges. Commonwealth Governance Handbook.

Lee, D. (2012). The Role of Transformational leadership in the Home Health Care Industry. Home Health Care Management \& Practice, 24(4), 169-174.

Mugenda, O. M., \& Mugenda, A. G. (2008). Research methods: Quantitative and qualitative approaches. Nairobi: ACTS Press.

Mukabi, F. K., Barasa, P. W., \& Viola, C. (2015). Devolved governance in Kenya: Is it a false start in transformational decentralization for development? International Journal of Economics, Finance and Management, 4(1), 27-37.

Osama, A. H., \& Issa, S. M. (2015). A pilot study: Vital methodological issue. Business: Theory and Practice, 16(1), 53-62.

Peprah, C., Oduro-Ofori, E., \& Asante-Wusu, I. (2015).Analysis of accessibility to water supply and sanitation services in the Awutu-Senya East Municipality, Ghana. Journal of Sustainable Development, 8(8), 310-325.

Phillips, R., \& Noland, J. (2010). Stakeholder engagement, discourse ethics and strategic management. International Journal of Management Reviews, 12(1), 33-45.

Saifuddin, A. (2009). Methods in Sample Surveys: Cluster Sampling. John Hopkins Bloomberg School of Public Health.

Serfonten J. (2010). The Impact of Strategic Leadership on Operational Strategy and Performance of Business Organizations in South Africa. PHD thesis, University of Stellenbosch, Stellenbosch, South Africa.

Shen, C., \& Zou, H. F. (2015). Fiscal decentralization and public services provision in China. Annals of Economics and Finance, 16(1), 53-78.

Wachira, N. S. (2014). Challenges and prospects for effective water conservation in Mwingi North District, Kitui County, Kenya.

Wagah, G. G., Onyango, G. M., \&Kibwage, J. K. (2010). Accessibility of water services in Kisumu municipality, Kenya. Journal of Geography and Regional Planning, 3(4), 114-125.

\section{Copyrights}

Copyright for this article is retained by the author(s), with first publication rights granted to the journal.

This is an open-access article distributed under the terms and conditions of the Creative Commons Attribution license (http://creativecommons.org/licenses/by/4.0/). 